\title{
Non-invasive quantitative measurement of colloid transport in meso-scale porous media using Time Lapse Fluorescence Imaging
}

Jonathan W. Bridge*, Steven A. Banwart, A. Louise Heathwaite ${ }^{1}$

Groundwater Protection and Restoration Group, Department of Civil and Structural Engineering, University of Sheffield, Broad Lane, Sheffield, S3 7HQ

${ }^{1}$ Centre for Sustainable Water Management, Lancaster Environment Centre, Lancaster University, LA1 4YQ

*j.bridge@ sheffield.ac.uk, Tel. +44 (0)114 2225785

Environmental Science and Technology

$24^{\text {th }}$ July, 2006

\section{CONTENTS}

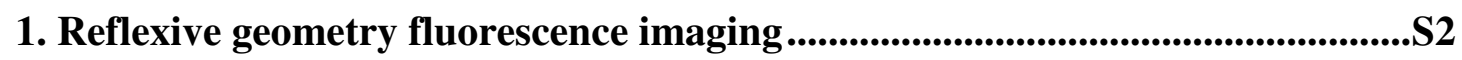

Estimation of penetration depth using the Beer-Lambert law ..............................S2

Table S2 - Comparison of reflexive UV time lapse fluorescence imaging with other

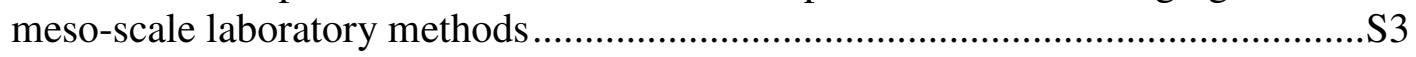

Effect of concentration peak truncation on analysis of $1^{\text {st }}$ spatial moment ............S4

2. Reproducibility and significance of results...................................................................S5

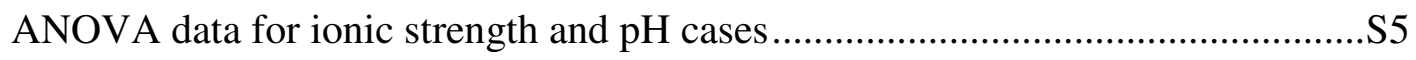

Paired t-tests for difference between solute and colloid data ...............................S6

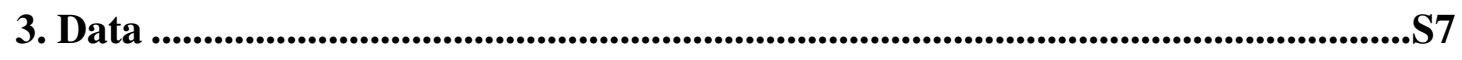

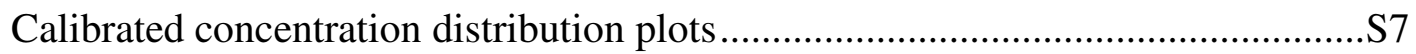

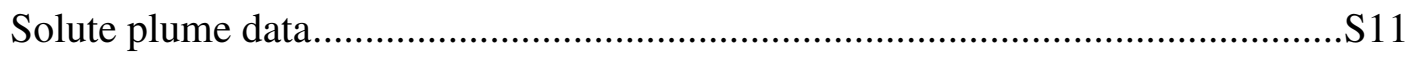

4. Parameter values for DLVO and attachment efficiency .................................S13

13 pages, 7 figures, 6 tables, 4 equations. 


\section{Reflexive geometry fluorescence imaging}

\section{Estimation of penetration depth using the Beer-Lambert law}

The Beer-Lambert law states that absorption,

$$
\begin{gathered}
\mathrm{A}=\varepsilon \mathrm{L} C \\
\mathrm{~A}=\log _{10}\left(\mathrm{I}_{0} / \mathrm{I}\right)
\end{gathered}
$$

where $\varepsilon=$ molar absorptivity (constant for a substance), $\mathrm{L}=$ path length through substance, $\mathrm{C}=$ concentration of substance, $\mathrm{I}_{0}=$ initial (incident) light intensity, $\mathrm{I}=$ intensity at distance L.

At input concentration (CML microspheres $20 \mathrm{mg} \mathrm{L}^{-1}$ suspended in fluorescein 0.02 $\mathrm{mM}$ ) were measured using a UV-Vis spectrophotometer (Biowave S2100, Biochrom, UK) to obtain A at excitation and emission wavelengths. This data was used to estimate the rate of reduction in excitation, $\mathrm{I}_{\mathrm{ex}}$, and fluorescence emission, $\mathrm{I}_{\mathrm{em}}$ per millimeter depth in the sand pack. These were then summed to give the proportional contribution to the detected signal with depth in the sand.

For estimation purposes, $100 \%$ quantum efficiency for the fluorophores was assumed. Further signal degradation by scattering by sand grains was not considered as it was observed that fluorescence escaped through the rear of the flow cell i.e. was transmitted through the sand thickness. Table S1 shows the results of the estimation including the profile of proportional contribution to the fluorescence signal with depth (last two columns). For both tracers the ratio of contribution to signal from the front :

\begin{tabular}{|c|c|c|c|c|c|c|}
\hline $\begin{array}{l}\text { Depth, } \\
\text { mm }\end{array}$ & $\begin{array}{l}\mathbf{I}_{\mathrm{ex}} / \mathbf{I}_{0}, \% \\
(\mathbf{3 5 0} \mathbf{~ n m})\end{array}$ & $\begin{array}{l}I_{e x} / I_{0}, \% \\
(455 \mathrm{~nm})\end{array}$ & $\begin{array}{l}\mathbf{I}_{\text {em }} / \mathbf{I}_{\mathbf{0}}, \% \\
(\mathbf{5 2 0} \mathbf{~ n m})\end{array}$ & $\begin{array}{l}\mathbf{I}_{\mathrm{em}} / \mathbf{I}_{0}, \% \\
(\mathbf{6 1 0} \mathbf{~ n m})\end{array}$ & $\begin{array}{l}\text { Colloid profile, } \\
\%\end{array}$ & $\begin{array}{l}\text { Solute profile, } \\
\%\end{array}$ \\
\hline $\mathbf{A}$ & 0.0231 & 0.0636 & 0.0266 & 0.023 & & \\
\hline 0 & 100 & 100 & 100 & 100 & 0 & 0 \\
\hline 1 & 94.82 & 86.37 & 94.05 & 94.84 & 19.20 & 24.47 \\
\hline 2 & 89.90 & 74.61 & 88.47 & 89.94 & 17.27 & 19.88 \\
\hline 3 & 85.25 & 64.44 & 83.21 & 85.31 & 15.53 & 16.15 \\
\hline 4 & 80.83 & 55.66 & 78.27 & 80.90 & 13.96 & 13.12 \\
\hline 5 & 76.64 & 48.08 & 73.62 & 76.73 & 12.56 & 10.66 \\
\hline 6 & 72.67 & 41.53 & 69.24 & 72.77 & 11.29 & 8.663 \\
\hline 7 & 68.91 & 35.87 & 65.13 & 69.02 & 10.15 & 7.038 \\
\hline
\end{tabular}
rear half of the bed thickness is $\sim 60: 40 \%$. Bias is slightly greater in fluorescein.

Table S1 - estimation of contribution to detected fluorescence signal. 
Table S2 - Comparison of reflexive UV time lapse fluorescence imaging with other meso-scale laboratory methods

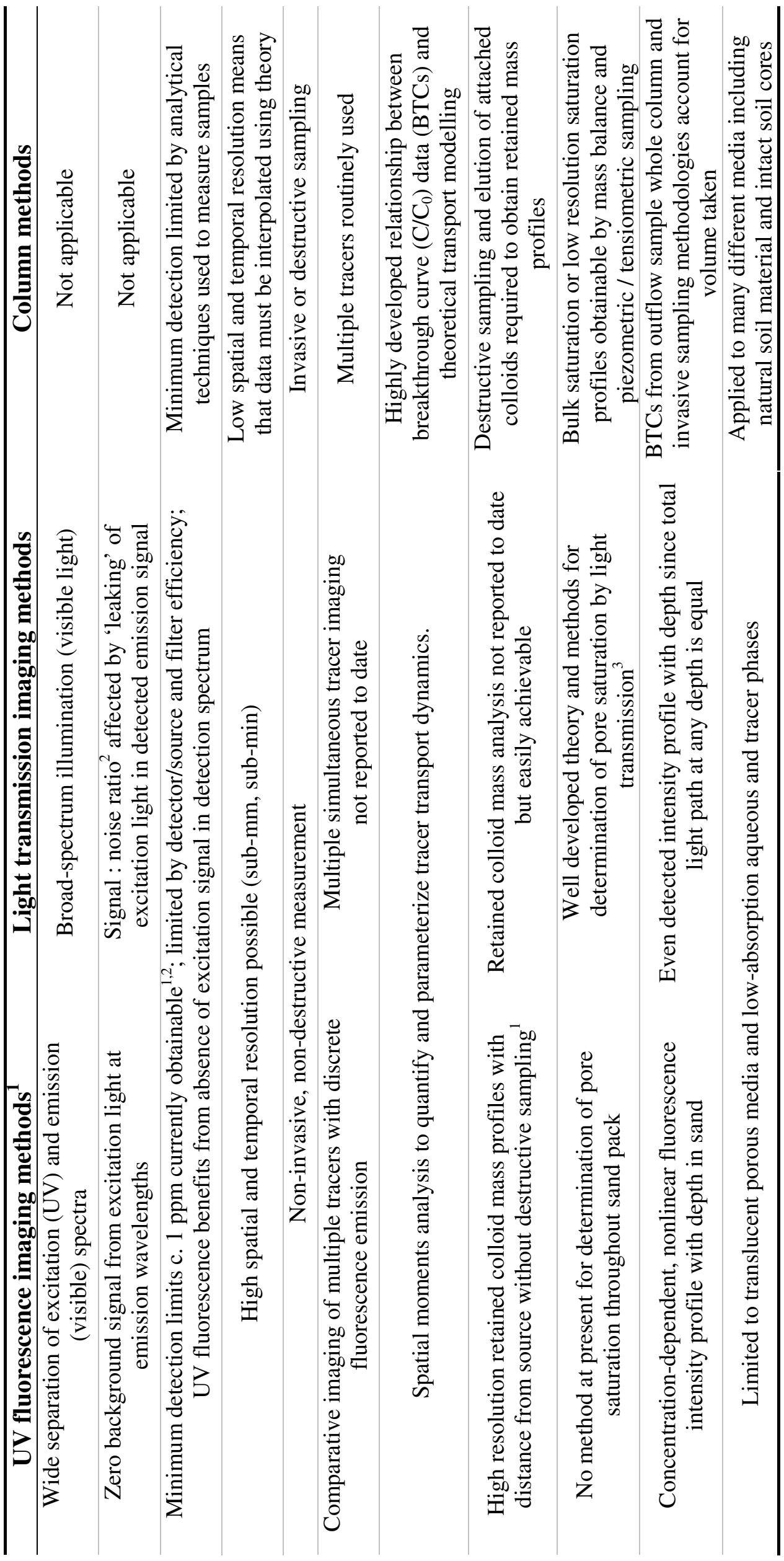

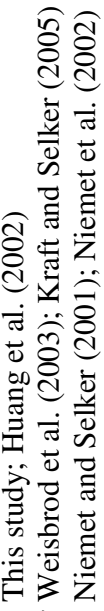




\section{Effect of concentration peak truncation on analysis of $1^{\text {st }}$ spatial moment}

To determine conservative behavior of the solute tracer, $1^{\text {st }}$ spatial moments for the measured solute and a conservative transport model based on time-averaged velocity and dispersion parameters were compared at several times during each experiment. No significant differences were observed, leading to the conclusion that the solute tracer data approximated conservative behavior within each experiment, to which the reactive colloid behavior could be compared. Since fluorescence measurements underestimated peak concentrations due to non-linearity of the reflexive fluorescence signal at high concentrations, truncation of the plumes occurred. We tested the effect of truncation of peak concentrations on measured $1^{\text {st }}$ spatial moment values by truncating the model conservative plume data at $0.015,0.01$ and $0.05 \mathrm{mM}$ (input concentration $0.02 \mathrm{mM}$ ). Figure $\mathrm{S} 1$ illustrates that truncation at $0.01 \mathrm{mM}$ is an approximation of the measured truncation in fluorescence images, and that at this level the variation in $1^{\text {st }}$ spatial moment between truncated and original plumes is less than $5 \%$ at any time interval used for comparison of measured and modeled solute plumes.

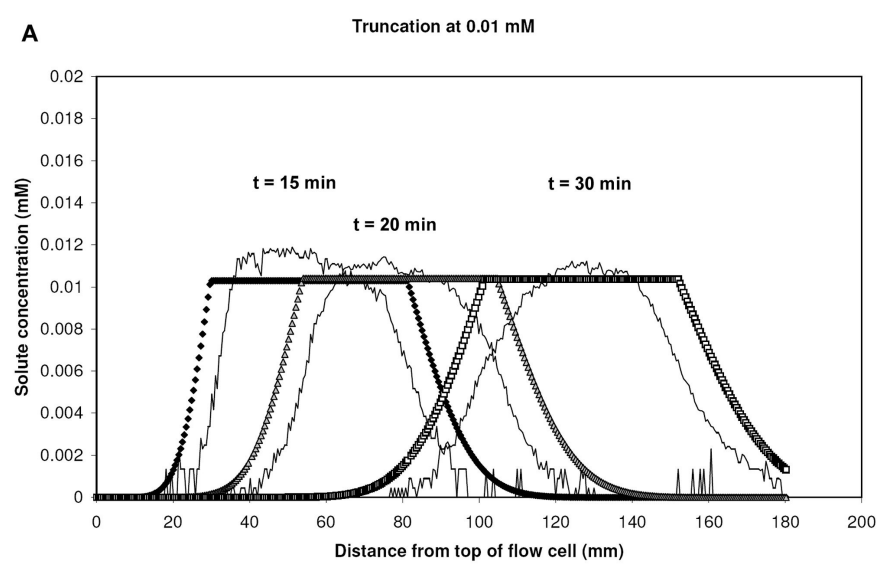

B

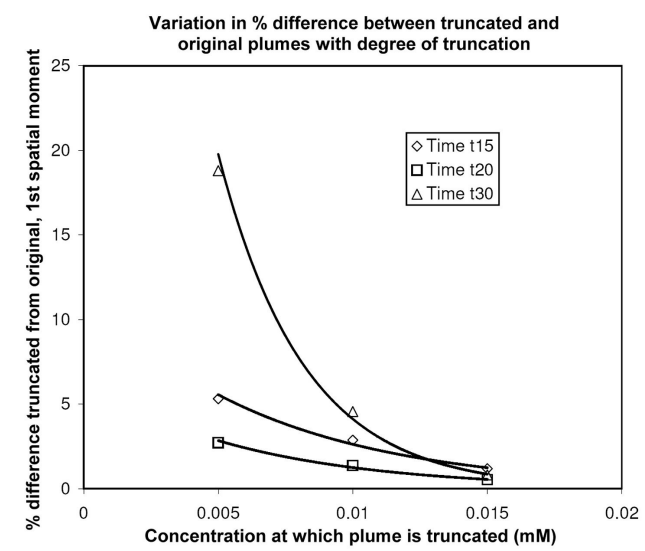

Figure S1: Effect of peak truncation on measured $1^{\text {st }}$ spatial moment values. 


\section{Reproducibility and significance of results}

\section{ANOVA data for ionic strength and $\mathrm{pH}$ cases}

Single factor ANOVA was carried out to assess the affect of experimental variables on solute and colloid $1^{\text {st }}$ spatial moment datasets.

Ionic strength was expected to have no effect on solute data but to influence colloid data because colloid deposition is known to increase with increasing ionic strength. Since colloid $1^{\text {st }}$ spatial moment data showed large differences between high and low ionic strength conditions, variance within the ionic strength dataset was predicted to be insignificant at low ionic strength and very significant at high ionic strength. This was confirmed to be the case for experiments at $2 \mathrm{~mL} \mathrm{~min}^{-1}$. At $1 \mathrm{~mL} \mathrm{~min}^{-1}$ flow rate ionic strength was shown to create statistically significant although not dramatic differences between solute data as well as colloid data. It is possible that the variation was due to alteration of flow pattern by clogging of pores by colloids.

ANOVA values exceeding $F_{\text {crit }}$ occurred only at late stages $(t=30 \mathrm{~min})$ in experiments at $2 \mathrm{~mL} \mathrm{~min}^{-1}$. More detailed experiments are required in order reduce standard deviation in the $\mathrm{pH}$ datasets and clarify any $\mathrm{pH}$ effect on colloid and solute transport.

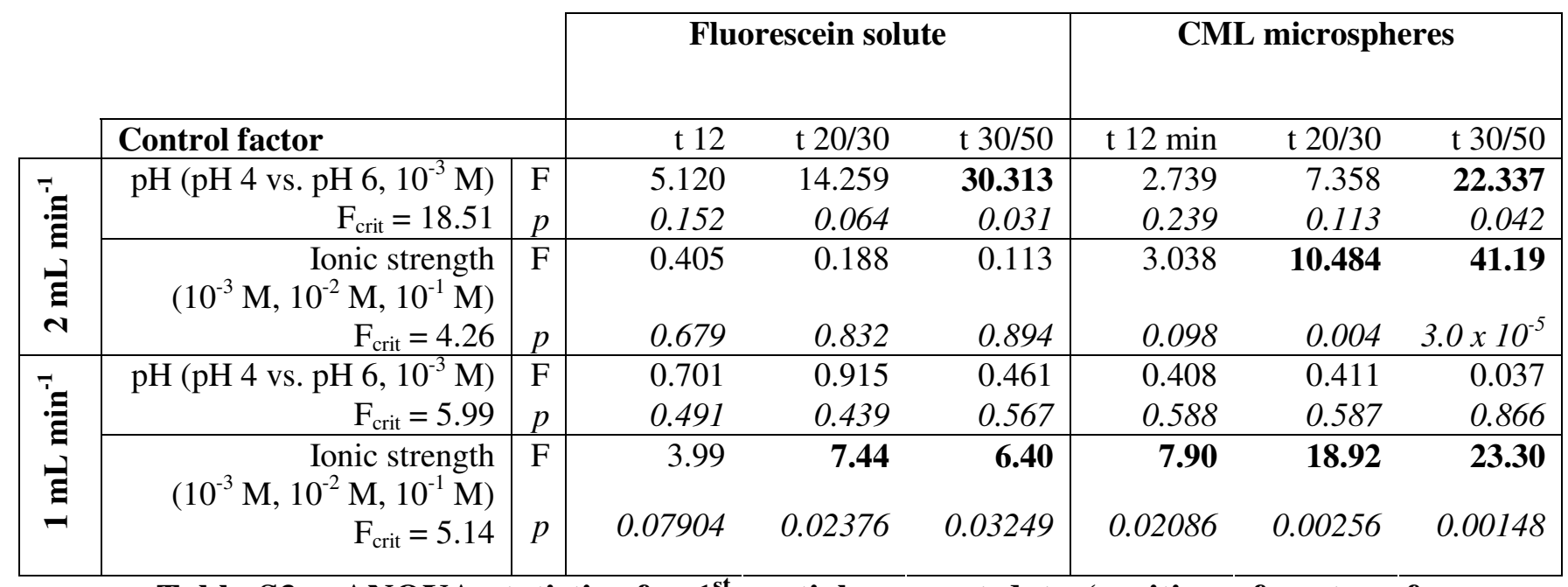

Table S3 - ANOVA statistics for $1^{\text {st }}$ spatial moment data (position of centre of mass) for fluorescein and CML colloid plumes at three times during colloid transport experiments. Values exceeding $F_{\text {crit }}$ are shown in bold type. 
Paired t-tests for difference between solute and colloid data

Simultaneous measurements of the solute and colloid tracers passing together through the same flow cell allowed paired t-tests to be employed in the analysis of differences between the two tracers under varying experimental conditions. Table S4 shows the results of one-tailed paired t-tests. Data compare the difference between solute and colloid data at a particular ionic strength. Significant differences between solute and colloid data occur and are characteristic of each ionic strength treatment at both flow rates. At $10^{-3} \mathrm{M}$, colloid mean centre of mass is located slightly ahead of the solute mean centre of mass (negative difference values) while at $10^{-1} \mathrm{M}$ the colloid mean centre of mass is significantly behind the solute mean. In all treatments over time, values become increasingly more positive reflecting significant trends in the colloid data over time.

\begin{tabular}{|c|c|c|c|c|c|c|c|c|c|c|}
\hline & \multicolumn{3}{|c|}{$10^{-3} \mathrm{M}$} & \multicolumn{3}{|c|}{$10^{-2} \mathrm{M}$} & \multicolumn{3}{|c|}{$10^{-1} M$} \\
\hline & & t 12 & t $20 / 30$ & t 30/50 & t 12 & t $20 / 30$ & t 30/50 & t 12 & t $20 / 30$ & t 30/50 \\
\hline \multirow{3}{*}{ 五 } & & -9.63 & $\begin{array}{l}-7.10 \\
\end{array}$ & -2.84 & -2.12 & 2.37 & 3.94 & 0.57 & 3.16 & 3.35 \\
\hline & $\mathrm{T}_{\text {crit }}$ & 2.35 & 2.35 & 2.35 & 2.92 & 2.92 & 2.92 & 6.31 & 2.92 & 2.92 \\
\hline & $p$ & 0.001 & 0.003 & 0.03 & 0.09 & 0.07 & 0.03 & 0.33 & 0.04 & 0.04 \\
\hline \multirow{3}{*}{$\underset{\mathrm{N}}{\mathrm{\Xi}}$} & & -8.14 & -5.34 & -6.76 & 1.18 & 2.17 & 3.09 & 2.85 & 3.71 & 4.77 \\
\hline & $\mathrm{T}_{\text {crit }}$ & 2.35 & 2.35 & 2.35 & 2.35 & 2.35 & 2.35 & 2.35 & 2.35 & 2.35 \\
\hline & $p$ & 0.002 & 0.006 & 0.003 & 0.16 & 0.06 & 0.03 & 0.03 & 0.017 & 0.009 \\
\hline
\end{tabular}

Table S4 - One-tailed t-test statistics for $1^{\text {st }}$ spatial moment data (position of centre of mass) for fluorescein and CML colloid plumes at three times during colloid transport experiments. 


\section{Data}

\section{Calibrated concentration distribution plots}

Figures S2-S5 and figure 3 (main text) show the influence of pore solution ionic strength on the evolving plume morphology of CML microspheres over time. As ionic strength increases from $10^{-3} \mathrm{M}$ to $10^{-1} \mathrm{M} \mathrm{NaCl}$, the advance of the colloid tracer through the cell is progressively retarded through greater immobilization of colloid particles within the quartz sand. This behavior is evident under all experimental conditions (flow rates of $2 \mathrm{~mL} \mathrm{~min}^{-1}$ and $1 \mathrm{~mL} \mathrm{~min}^{-1}$; $\mathrm{pH} 4$ and $\mathrm{pH} 6$ ).

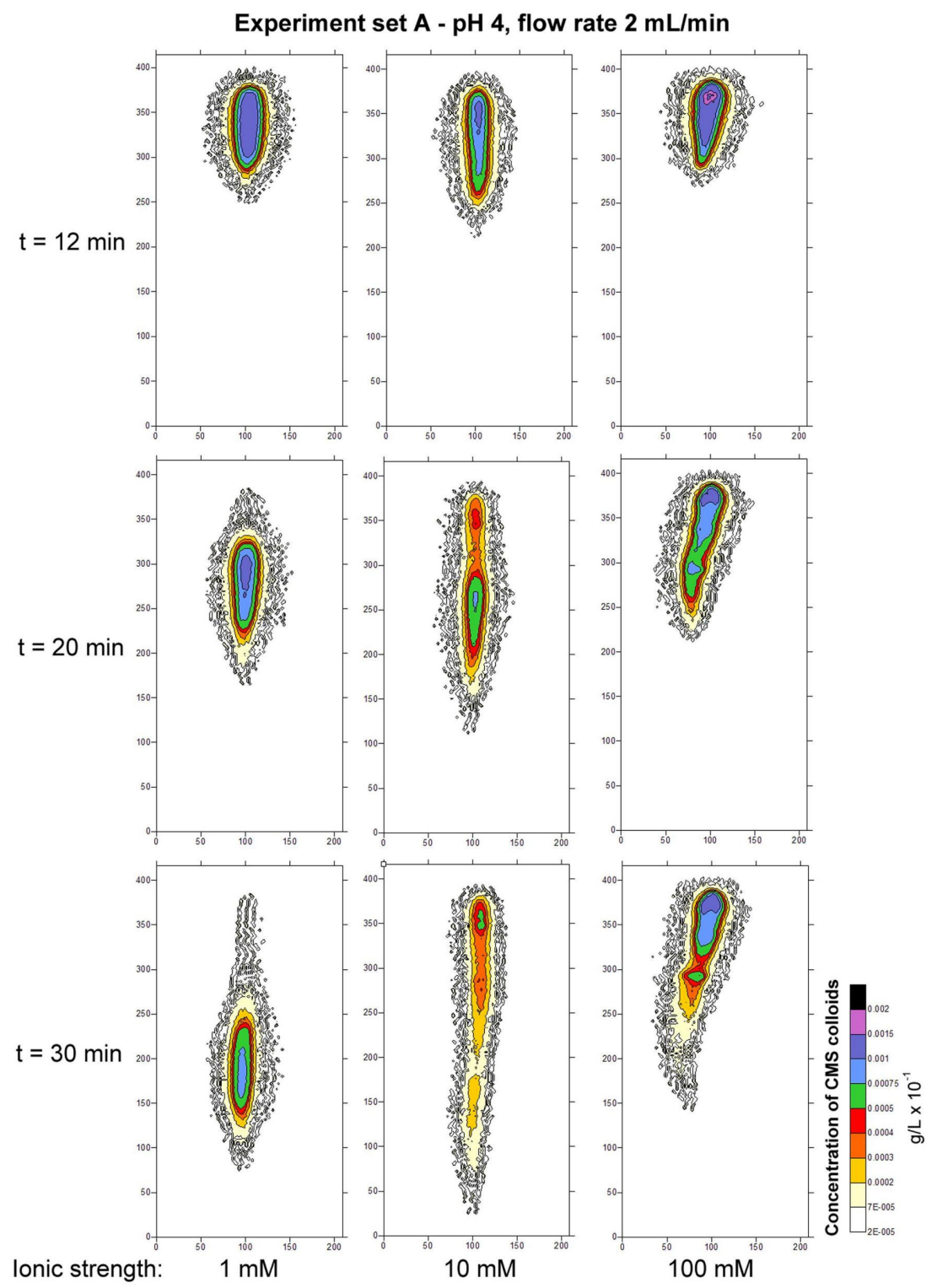

Figure S2: Calibrated concentration maps showing CML colloid plumes over time at $\mathrm{pH} \mathrm{4,} 2 \mathrm{~mL} \mathrm{m^{-1 }}$ flow rate and $10^{-3}, 10^{-2}, 10^{-1} \mathrm{M}$ ionic strength (columns). 


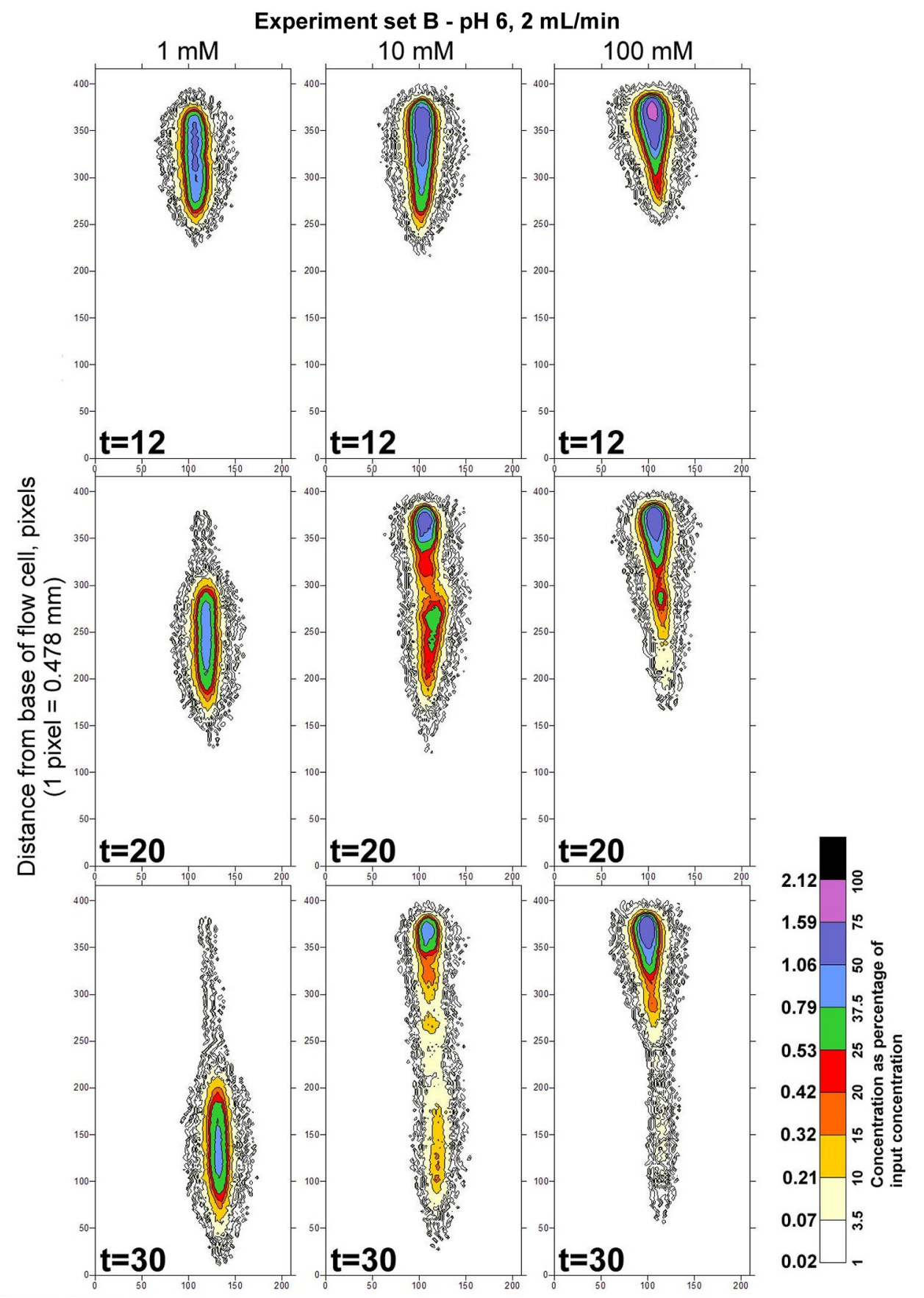

Figure S3: Calibrated concentration maps showing CML colloid plumes over

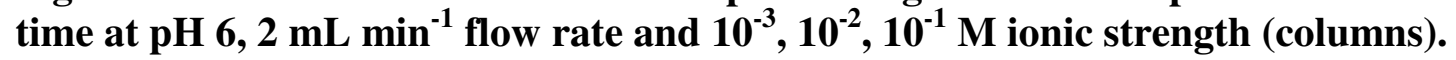


Experiment set $\mathrm{C}$ - $\mathrm{pH} \mathrm{4}$, flow rate $1 \mathrm{~mL} / \mathrm{min}$
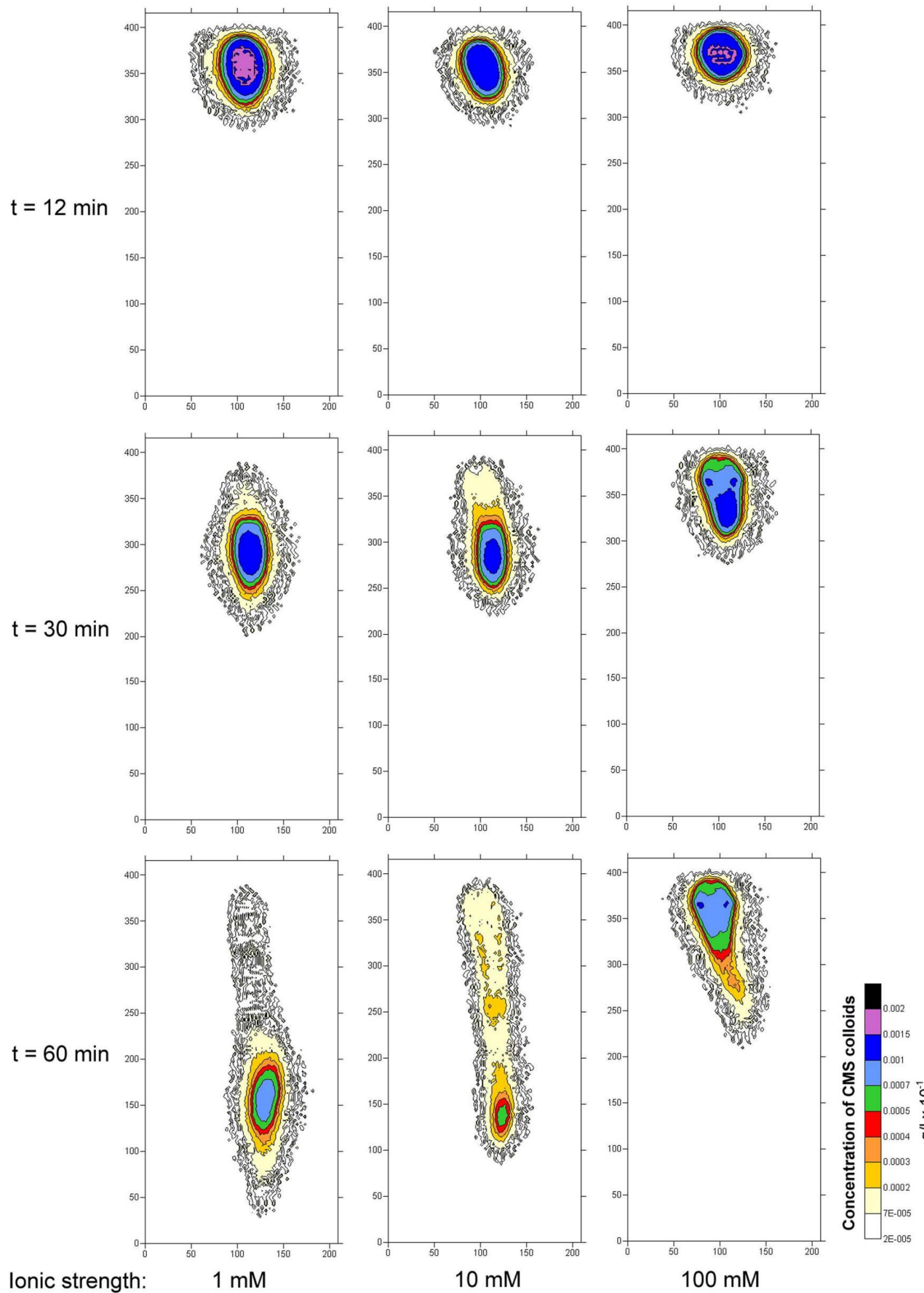

Figure S4: Calibrated concentration maps showing CML colloid plumes over

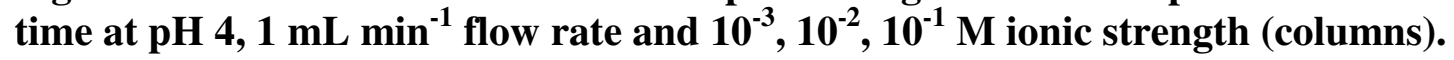


Experiment $\mathrm{D}$ - flow rate $1 \mathrm{~mL} / \mathrm{min}, \mathrm{pH} 6$
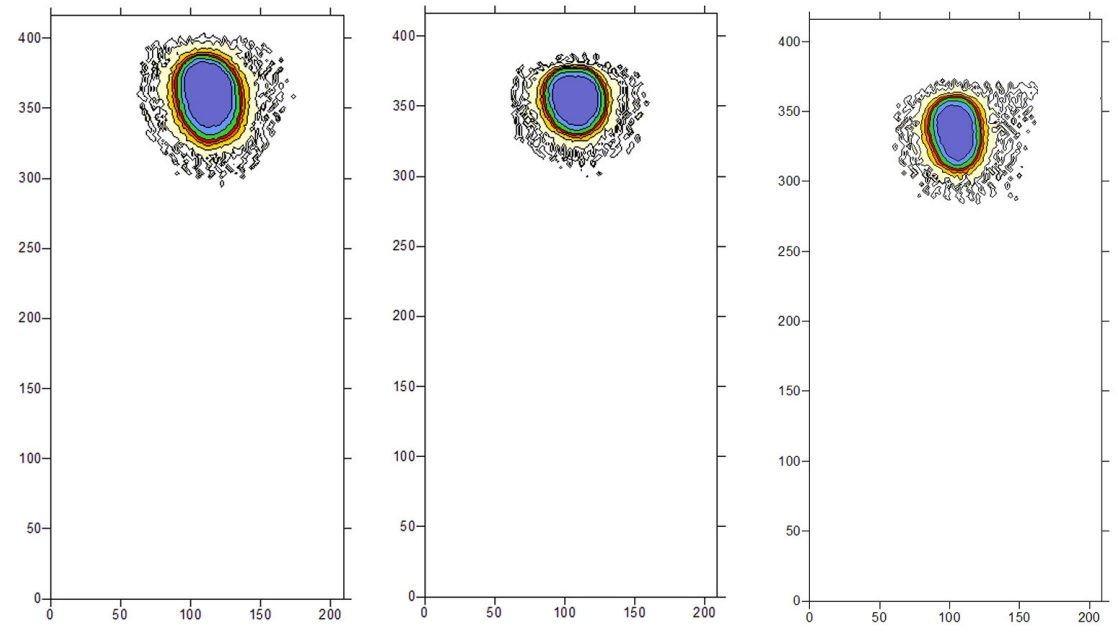

$t=12 \min$
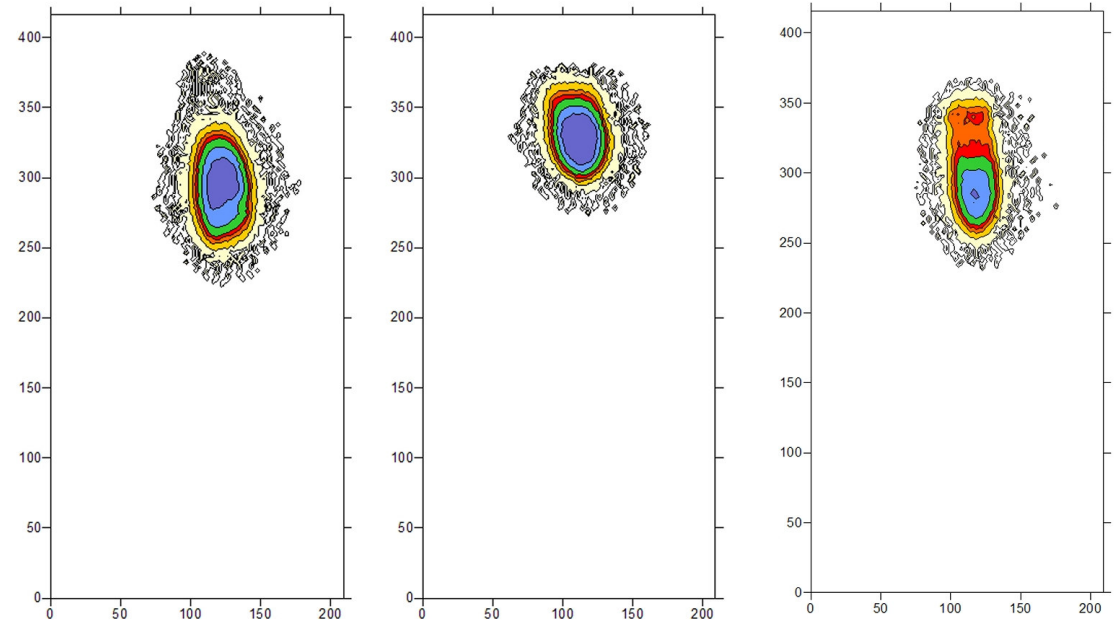

$\mathbf{t}=\mathbf{3 0} \mathrm{min}$
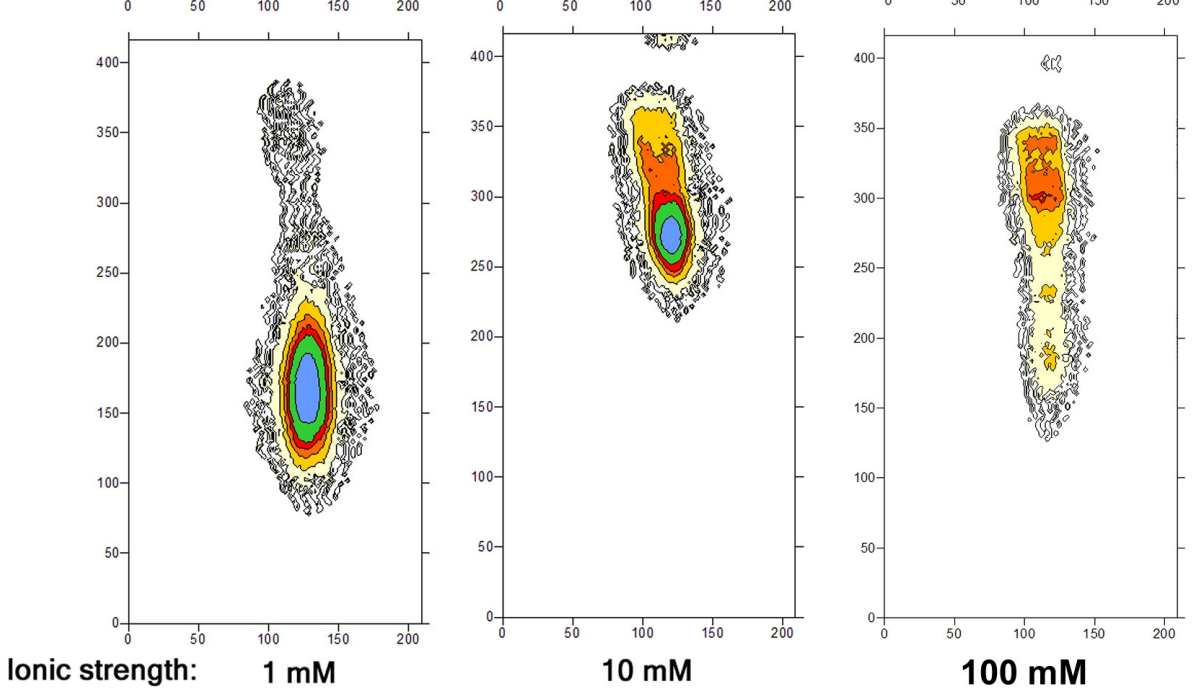

$t=60 \min$

Figure S5: Calibrated concentration maps: CMS colloid tracer plumes over time

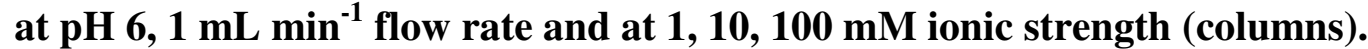




\section{Solute plume data}

This study was focused on detection and quantitative measurement of colloid tracer by fluorescence imaging. The solute was used as a benchmark for colloid behavior and was shown to behave as a conservative tracer. For completeness, Figures S6 and S7 show calibrated concentration distribution plots and spatial moments / mass balance data for the solute tracer.

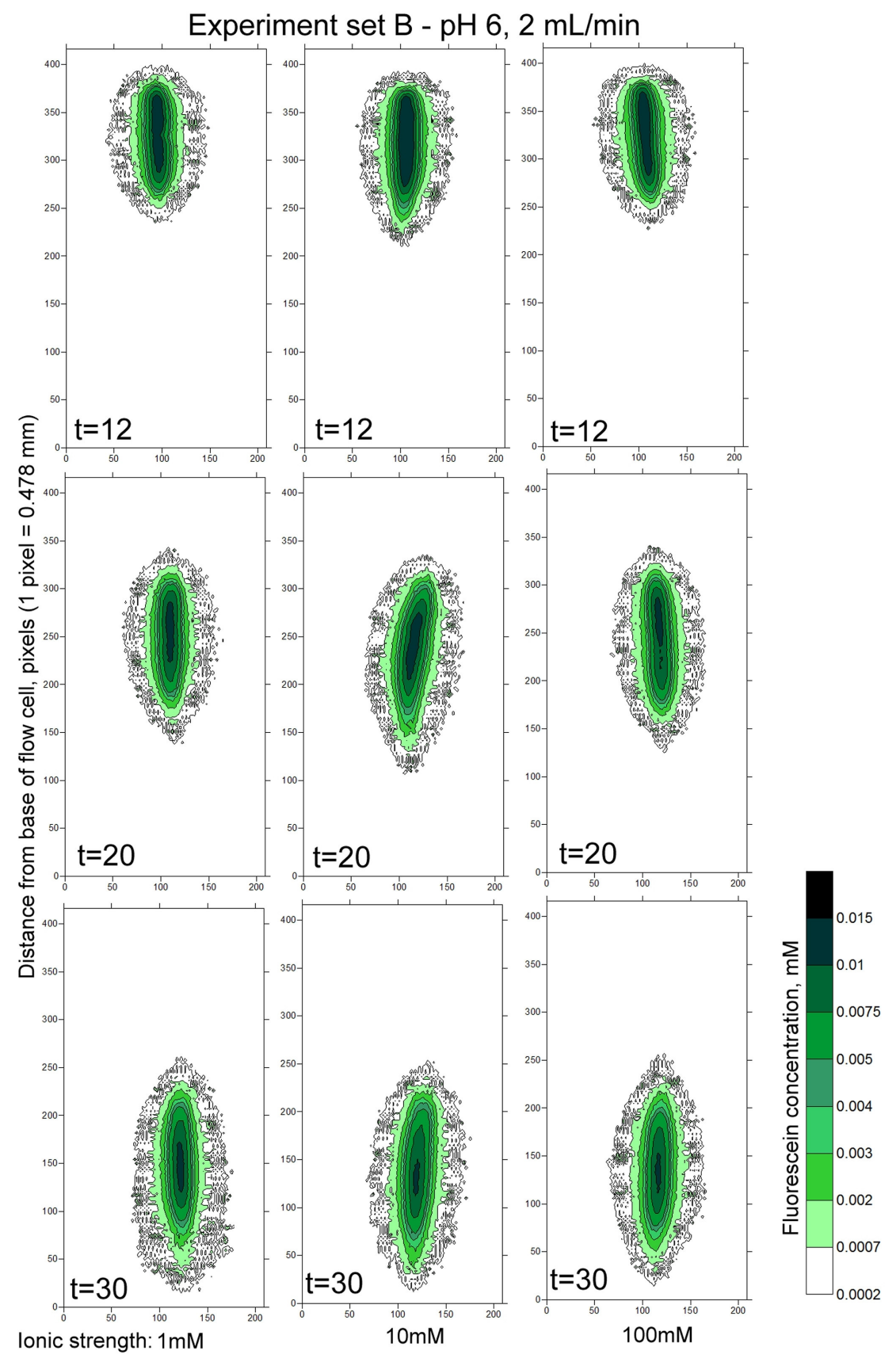

Figure S6: Calibrated concentration map data showing solute plume movement through the flow cell at $2 \mathrm{~mL} \mathrm{m^{-1 }}$ flow rate, pH 6 for three ionic strength conditions $(1,10,100 \mathrm{mM})$. Data from experiment set $\mathrm{B}$, replicate 2 . Solute was passing through cell simultaneously with colloid shown in Figure S2 and direct comparison can be made. 


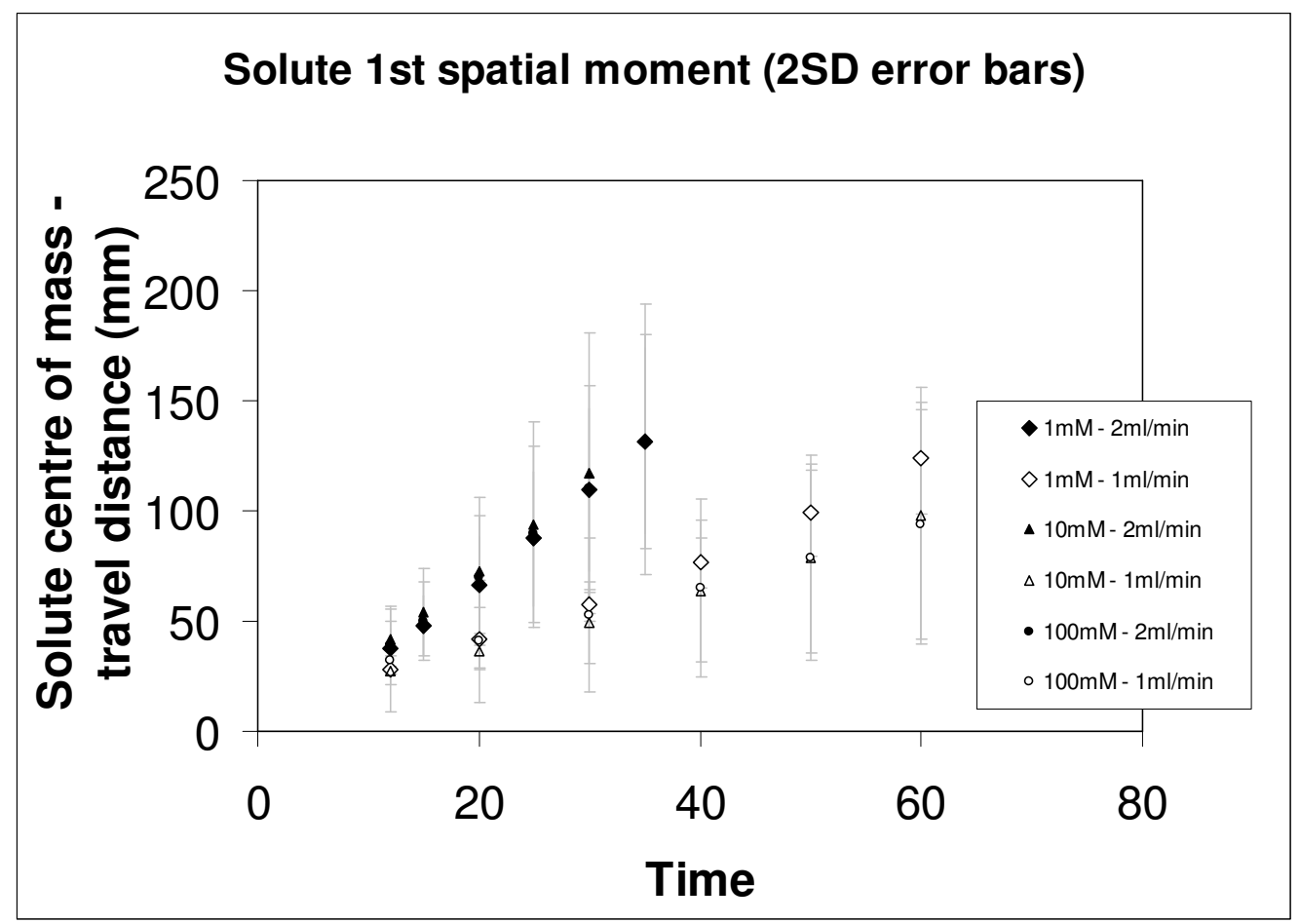

Figure S7a: $1^{\text {st }}$ spatial moment (position of center of mass) for the solute fluorescein tracer plotted against time after injection. Data points are the mean of replicates at the same ionic strength $\left(10^{-3} \mathrm{M}\right.$ to $\left.10^{-1} \mathrm{M} \mathrm{NaCl}\right)$.

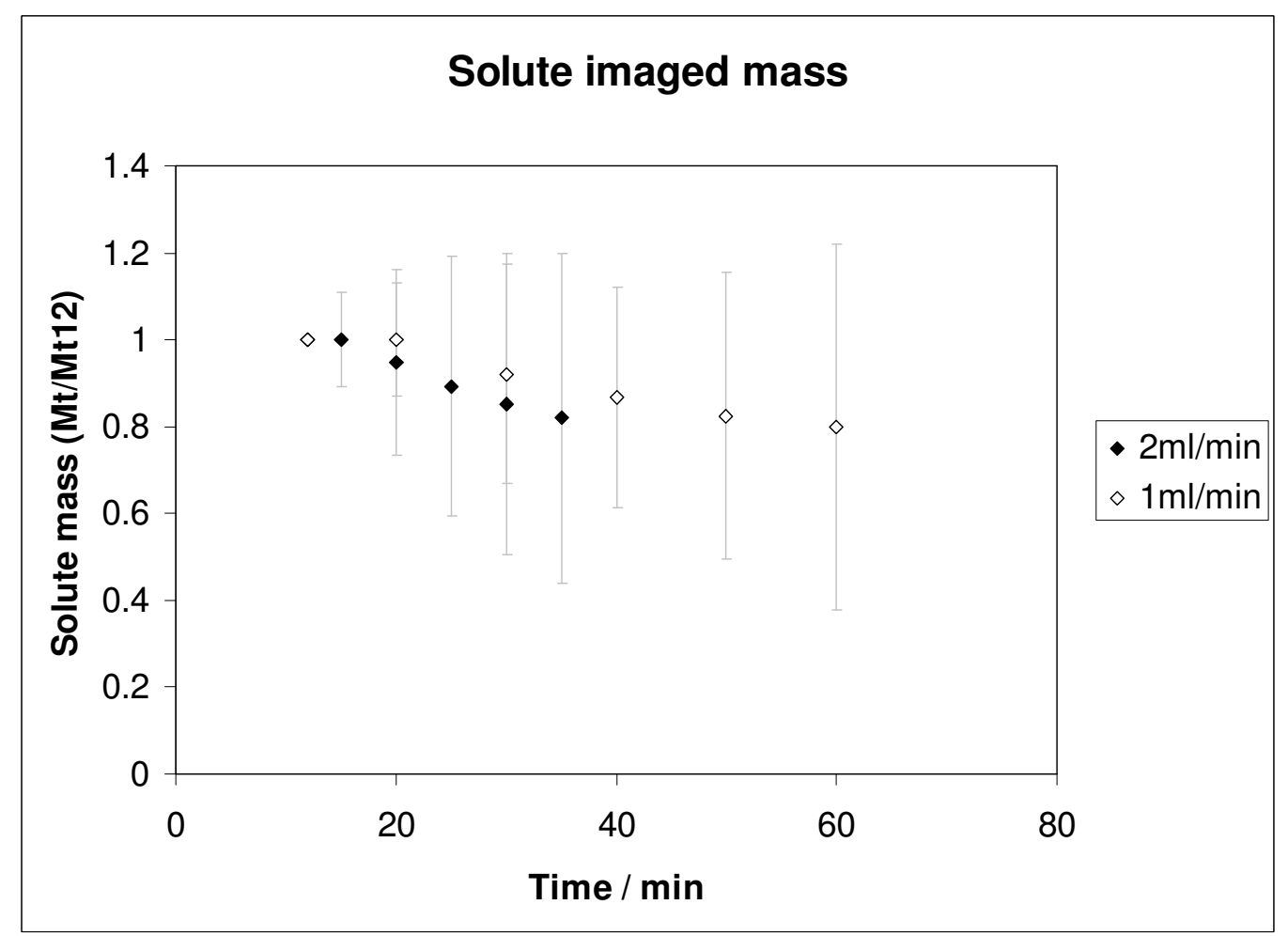

Figure S7b: Variation in mean solute tracer detected mass $\left(M / M_{0}\right)$ where $M_{0}=$ mass detected in first image after injection. Errors are 2SD. Relative decrease is the same at both flow rates making mass loss due to reactive behavior unlikely. Decrease is more likely due to photodegradation of the tracer under exposure to UV light during imaging; this exposure time was the same for both flow rates. 


\section{Parameter values for DLVO and attachment efficiency}

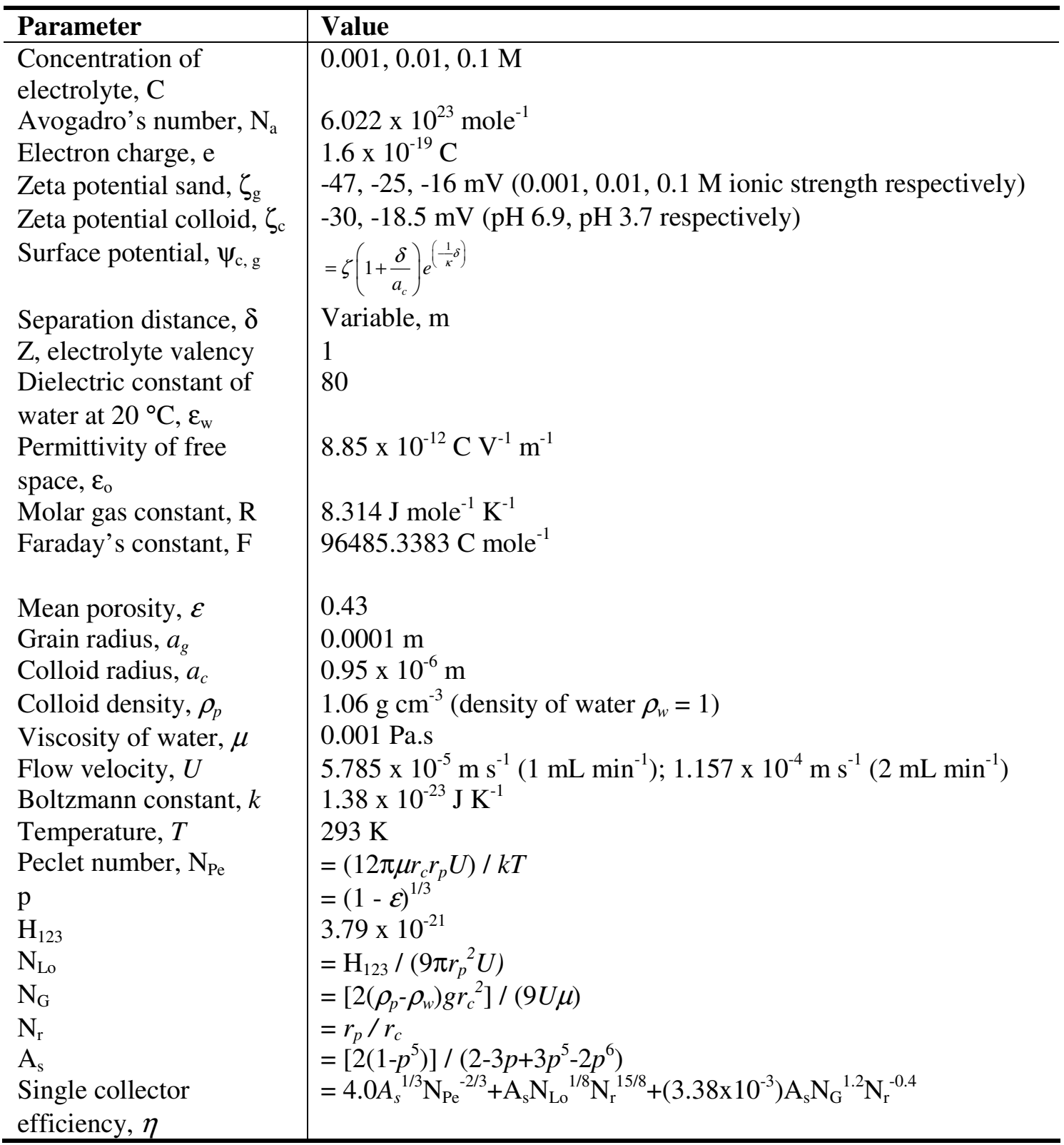

Table S6 - Parameters for determination of DLVO and attachment efficiency, $\alpha$

Double layer thickness is $1 / \kappa$ where:

$$
\kappa^{2}=\frac{\left(2 F^{2} C 10^{-3}\right)}{\varepsilon \varepsilon_{o} R T}
$$

$\gamma_{\mathrm{c}}$ and $\gamma_{\mathrm{g}}$ are functions of colloid and sand surface potentials, respectively, where:

$$
\gamma_{c, g}=\tanh \left(\frac{Z e \psi_{c, g}}{4 k T}\right) .
$$

